\title{
PGPR enhanced phytoremediation of petroleum contaminated soil and rhizosphere microbial community response
}

\author{
Jinyu Hou ${ }^{\mathrm{a}, \mathrm{b}}$, Wuxing Liu ${ }^{\mathrm{a}, *}$, Beibei Wang ${ }^{\mathrm{a}, \mathrm{b}}$, Qingling Wang ${ }^{\mathrm{a}}$, Yongming Luo ${ }^{\mathrm{a}, \mathrm{c}}$, Ashley E. Franks ${ }^{\mathrm{d}}$ \\ ${ }^{a}$ Key Laboratory of Soil Environment and Pollution Remediation, Institute of Soil Science, Chinese Academy of Sciences, Nanjing 210008 , China \\ ${ }^{\mathrm{b}}$ University of Chinese Academy of Sciences, Beijing 100049, China \\ ${ }^{\mathrm{c}}$ Institute of Coastal Zone Research, Chinese Academy of Sciences, Yantai 264003, China \\ ${ }^{\mathrm{d}}$ Department of Physiology, Anatomy and Microbiology, La Trobe University, Bundoora, Victoria 3086, Australia
}

\section{H I G H L I G H T S}

- PGPR can enhance C21-C34 fraction of TPH removal during phytoremediation.

- Petroleum removal was irrelative with bacterial community diversity.

- Specific degraders and biosurfactant producers were the driving factor of TPH removal.

\section{A R T I C L E I N F O}

\section{Article history:}

Received 3 April 2015

Received in revised form 30 June 2015

Accepted 9 July 2015

Available online 24 July 2015

\section{Keywords:}

Petroleum pollutant

Phytoremediation

PGPR

16s rRNA

High-throughput pyrosequencing

\begin{abstract}
A B S T R A C T
The aim of this study was to investigate petroleum phytoremediation enhancement by plant growth promoting bacteria (PGPR), specifically the correlation between petroleum hydrocarbon fractions and bacterial community structure affected by remediation and PGPR inocula. Aged petroleum contaminated soil was remediated by tall fescue (Testuca arundinacea L.) inoculated with two PGPR strains. Hydrocarbon degradation was measured by GC-MS (Gas-chromatography Mass-spectrometer) based on carbon fraction numbers (C8-C34). Changes in bacterial community structure were analyzed by high-throughput pyrosequencing of 16s rRNA. PGPR inoculation increased tall fescue biomass and petroleum hydrocarbons were removed in all the treatments. Maximum hydrocarbon removal, particular high molecular weight (C21-C34) aliphatic hydrocarbons (AHs) and polycyclic aromatic hydrocarbons (PAHs), was observed in tall fescue inoculated with PGPR. The relative abundance of phyla $\gamma$-proteobacteria and Bacteroidetes increased after different treatments compared with controls. Moreover, a bacterial guild mainly comprising the genera Lysobacter, Pseudoxanthomonas, Planctomyces, Nocardioides, Hydrogenophaga, Ohtaekwangia was found to be positively correlated with C21-C34 petroleum hydrocarbons fractions removal by RDA analysis, implying that petroleum degradation was unrelated to bacterial community diversity but positively correlated with specific petroleum degraders and biosurfactant producers.
\end{abstract}

(c) 2015 Elsevier Ltd. All rights reserved.

\section{Introduction}

Petroleum contamination continues to be of serious environmental concern due to the sustained growth of crude oil extraction and associated production (Jurelevicius et al., 2013). This has led to a search for sustainable methods for the remediation of contaminated environments (Pizarro-Tobías et al., 2015). Phytoremediation for the in situ remediation for petroleum contaminated soil is being seen as an efficient, sustainable and cost-effective remediation technique compared to conventional

\footnotetext{
* Corresponding author.

E-mail address: liuwuxin@issas.ac.cn (W. Liu).
}

physical-chemical techniques (Pizarro-Tobías et al., 2015). During phytoremediation, biodegradation of petroleum organic components is promoted by the synergy between plants and the microorganisms present in the rhizosphere, the region of soil that is directly influenced by root secretions (Yateem, 2013).

Successful phytoremediation is dependent on the survival and growth of plants on contaminated sites, as well as the ability of the rhizosphere to support an active soil microbial population (Cook and Hesterberg, 2013). In contaminated areas, soil microbial populations are often restricted by petroleum toxins and nutrient deficiency (Wang et al., 2011). To promote phytoremediation, contaminant-tolerant plant species with rapid growth characters and vigorous root system, like tall fescue, have been utilized 
(Liu et al., 2014). Plant growth promoting rhizobacteria (PGPR) have also been used as inocula to further increase plant growth, reduce environmental stress and promote degradation by rhizosphere-associated microorganism (Khan et al., 2013).

Numerous pot experiments and field trials have reported success in total petroleum hydrocarbon removal utilizing PGPR inocula in association with tolerant plants (Agarry et al., 2013; Liu et al., 2013). The survival of introduced PGPR, and subsequent changes to the rhizosphere associated microbial community structure, are considered to be key factors for successful phytoremediation (Agarry et al., 2013). However, studies reporting changes in the microbial community have been mostly performed by traditional techniques such as T-RFLP and DGGE (Ribeiro et al., 2013; Wei et al., 2014). These techniques often have a low taxonomic resolution and do not provide information on low abundance microbial species in the rhizosphere. In recent years, high-throughput sequencing technologies with the advantages of high throughput and low cost, like the Illumina platform, are becoming more widely used and allow analysis of microbial community diversity through 16s rRNA analysis (Das and Kazy, 2014).

Considerable attention has been paid to total petroleum hydrocarbons (TPHs) removal efficiency during phytoremediation. However, this may not be suitable as petroleum hydrocarbon is a very complex mixture composed mainly of aliphatic hydrocarbons (AHs) and polycyclic aromatic hydrocarbons (PAHs), each with different carbon chain lengths and structures with different physicochemical and toxicity properties. The variation in the relative abundance of these components is potentially important in influencing the degradation efficiency and bacterial activity (Hamamura et al., 2013). Therefore, more comprehensive analysis of petroleum hydrocarbon is required and fractionation, in terms of aliphatic and aromatic compounds, and Equivalent Carbon Number (EC), determined by GC-MS, would be useful in such studies.

To better elucidate the mechanisms of phytoremediation enhancement by PGPR, particularly the correlation between bacterial community and components of petroleum hydrocarbons, a pot experiment using tall fescue plants was designed in weathered petroleum contaminated soil. The affects of fertilization, planting only, and planting with two PGPR strains were studied using GC-MS, Illumina sequencing and multivariate statistic analysis to monitor the different fractions of petroleum hydrocarbons and bacterial community to elucidate their relationship in the PGPR assisting phytoremediation process.

\section{Material and methods}

\subsection{Soil and bacterial strains}

Weathered contaminated soil was collected near an individual oil production well at Shengli oilfield, Shandong province, China (available nitrogen, $34.0 \mathrm{mg} \mathrm{kg}^{-1}$; available $\mathrm{P}, 28.0 \mathrm{mg} \mathrm{kg}^{-1} ; \mathrm{pH}$, 8.7; salt content, $0.17 \%$ ).

PGPR strains Klebsiella sp. D5A and Pseudomonas sp. SB were obtained from the Key Laboratory of Soil Environment and Pollution Remediation, Institute of Soil Science, Chinese Academy of Sciences, Nanjing, China. They had been deposited in the Chinese Culture Collection Management Committee General Microbiology Center (CGMCC), accession numbers are CGMCC Nos. 7248 and 7246, respectively.

\subsection{Pot experiment}

Tall fescue seeds were sterilized in 70\% ethanol for $2 \mathrm{~min}$ and in $1 \%$ sodium hypochlorite for $10 \mathrm{~min}$ then rinsed twice with sterile water before planting. Experimental design consisted of 5 treatments in 3 replicates. The five treatments were: (1) no-fertilizer (Control); (2) fertilizer $(F)$; (3) fertilizer + tall fescue (FP); (4) fertilizer + tall fescue + Klebsiella sp. D5A (FP + D5A); and (5) fertilizer + tall fescue + Pseudomonas sp. SB $(\mathrm{FP}+\mathrm{SB})$. Plant pots were filled with $2.0 \mathrm{~kg} 4-\mathrm{mm}$ sieved air-dry soil and water content of the soil was maintained at about $60 \%$ field capacity during the experimental period. Inorganic nutrients $\left(\mathrm{NH}_{4}\right)_{2} \mathrm{SO}_{4}$ and $\mathrm{K}_{2} \mathrm{HPO}_{4}$ were added to all treatments except control to give a final rates of $250 \mathrm{mg} \mathrm{N} \mathrm{kg}^{-1}$ and $100 \mathrm{mg} \mathrm{P} \mathrm{kg}^{-1}$.

PGPR inoculation treatments were prepared by centrifugation at $9000 \mathrm{rpm}$ for $15 \mathrm{~min}$ at $4{ }^{\circ} \mathrm{C}$ of exponential growth phase cultures grown in Luria Broth medium. Cell pellets were washed with sterile distilled water before resuspension in sterile distilled water to form inocula with a density of $10^{9}$ colony-forming units (cfus) $\mathrm{mL}^{-1}$. PGPR inocula $\left(15 \mathrm{~mL} \mathrm{pot}^{-1}\right)$ were mixed with soil before planting to give a final inoculation of $10^{7} \mathrm{cfus} \mathrm{kg}^{-1}$ soil in accordance with Bashan (1986). Plants were grown for 4 months in a sunlight greenhouse. At harvest, the roots and shoots of plants were collected and washed with deionized water. Soil from each pot was sampled and stored at $4{ }^{\circ} \mathrm{C}$ for TPH analysis or $-80^{\circ} \mathrm{C}$ for microbial community analysis. Dry weights of the shoots and roots were measured.

\subsection{Quantification of petroleum hydrocarbons}

Soil samples were lyophilized and passed through a $0.25-\mathrm{mm}$ sieve before TPH analysis. Aliquots of $2 \mathrm{~g}$ of the soil sample were mixed with $2 \mathrm{~g}$ of anhydrous sodium sulfate and extracted using $70 \mathrm{~mL}$ dichloromethane in a Soxhlet extractor for $24 \mathrm{~h}$. The extracts were rotary-evaporated while being solvent-exchanged into $10 \mathrm{~mL}$ of hexane. The hexane extract was centrifuged and $3 \mathrm{~mL}$ of supernatant was chromatographed on a $0.5 \mathrm{~cm}$ (i.d.) $\times 20 \mathrm{~cm}$ column containing $0.5 \mathrm{~g}$ anhydrous sodium sulfate, $2 \mathrm{~g}$ aluminum oxide and $3 \mathrm{~g}$ activated silica gel (200-325 mesh size) from top to bottom. The fraction of aliphatic hydrocarbons was eluted by $30 \mathrm{~mL}$ of hexane before the fraction of polycyclic aromatic hydrocarbons was eluted by $15 \mathrm{~mL}$ of a $2 / 1$ mixture of dichloromethane/hexane from the column. The eluates were concentrated to $2 \mathrm{~mL}$ for GC-MS analysis.

GC-MS analysis was performed using an Agilent 7890 GC-5975 MSD fitted with a capillary column (RESTEK, USA) DB-5 ms ( $30 \mathrm{~m} \times 0.25 \mathrm{~mm}$ i.d., $0.25 \mu \mathrm{m}$ ). For fractions of aliphatic hydrocarbons, the carrier gas was He at $1.4 \mathrm{~mL} \mathrm{~min}^{-1}$; the injection temperature was $300{ }^{\circ} \mathrm{C}$; the temperature program was: $50{ }^{\circ} \mathrm{C}$ (hold $5 \mathrm{~min}$ ) to $45^{\circ} \mathrm{C}$ at $2{ }^{\circ} \mathrm{C} \mathrm{min}^{-1}$ and then to $310^{\circ} \mathrm{C}$ (hold $10 \mathrm{~min}$ ) at $20^{\circ} \mathrm{C} \mathrm{min}^{-1}$. For fractions of polycyclic aromatic hydrocarbons, the carrier gas was He at $1.4 \mathrm{~mL} \mathrm{~min}^{-1}$; the injection temperature was $280^{\circ} \mathrm{C}$; the temperature program was: $50^{\circ} \mathrm{C}$ (hold $3 \mathrm{~min}$ ) to $40{ }^{\circ} \mathrm{C}$ at $2{ }^{\circ} \mathrm{C} \mathrm{min}-1$ and then to $300^{\circ} \mathrm{C}$ (hold $5 \mathrm{~min}$ ) at $25{ }^{\circ} \mathrm{C} \mathrm{min}{ }^{-1}$. The setup of external standard calibrations and quantity analysis of different fractions were following the WSDE (1997) method.

\subsection{Soil DNA extraction and PCR amplification}

Microbial DNA was extracted from $2 \mathrm{~g}$ of soil from each replicate of the five treatments using a soil DNA kit (Fast DNA SPIN for soils, MP Biomedicals, Solon, OH). The V4-V5 region of the bacteria 16 s ribosomal RNA gene were amplified by PCR $\left(95^{\circ} \mathrm{C}\right.$ for $2 \mathrm{~min}$, followed by 25 cycles at $95^{\circ} \mathrm{C}$ for $30 \mathrm{~s}, 55^{\circ} \mathrm{C}$ for $30 \mathrm{~s}$, and $72{ }^{\circ} \mathrm{C}$ for $30 \mathrm{~s}$ and a final extension at $72{ }^{\circ} \mathrm{C}$ for $5 \mathrm{~min}$ ) using primers 515F 5'-barcode- GTGCCAGCMGCCGCGG-3' and 907R 5'-CC GTCAATTCMTTTRAGTTT- $3^{\prime}$, where the barcode is an eight-base sample-specific sequence. PCR reactions were performed in triplicate $20 \mu \mathrm{L}$ mixture containing $4 \mu \mathrm{L}$ of $5 \times$ FastPfu Buffer, $2 \mu \mathrm{L}$ of $2.5 \mathrm{mM}$ dNTPs, $0.8 \mu \mathrm{L}$ of each primer $(5 \mu \mathrm{M}), 0.4 \mu \mathrm{L}$ of FastPfu 
Polymerase, and $10 \mathrm{ng}$ of template DNA. Paired-end sequenced $(2 \times 250)$ Sequencing was conducted on Illumina MiSeq platform by Majorbio Bio-pharm Technology Co., Ltd. (Shanghai, China).

\subsection{Data analysis}

Sequence reads were trimmed by Trimmomatic (Bolger et al., 2014); after trimming, reads were assembled by Flash software (Magoč and Salzberg, 2011) for further analysis by MOTHUR 1.33.0 (Kozich et al., 2013). Unique sequences were aligned to the reference SILVA database by default settings and chimeric sequences were removed. Sequences passing these screens were classified using a Ribosomal Database Project naïve Bayesian rRNA classifier with a confidence of $80 \%$. At each taxonomic level, the proportion of sequence identities was calculated as a percent of all sequences classified in that sample. OTUs (operational taxonomic units) were classified at similarities of $97 \%$ after normalized to 7369 sequences per sample. The $\alpha$-diversity indices, including observed OTUs (Sobs), Chao, Ace, InvSimpson and Shannon, were calculated using MOTHUR. Bacterial community structure, based on the OTU composition, was preformed by principal coordinates analysis (PCoA) conducted in $\mathrm{R}$ (Version 3.1.2). The correlation between the frequencies of top 30 abundant genera of each treatment, treatment type and degradation of petroleum hydrocarbon fractions was compared by RDA with Monte Carlo permutation test in $\mathrm{R}$ software. The Monte Carlo tests were based on 1000 random permutations of the data. The nucleotide sequences produced in the current study have been deposited in the European Nucleotide Archive under accession number PRJEB8995.

\subsection{Statistical analysis}

Statistical analysis was conducted with SAS 9.1 software. Duncan's multiple range tests were used to compare the means of treatments; variability in the data was expressed as the standard errors. All analyses were performed at the $p<0.05$ level.

\section{Results}

\subsection{Plant biomass and soil properties}

Shoot biomass showed no significant difference between treatments, however, tall fescue inoculated with D5A had a significantly greater root biomass than other treatments (Table 1). Of the four soils physicochemical properties determined (Table 1 ), only available phosphorus had significant difference between treatments. Available phosphorus was significantly lower in the control and reduced in the FP compared to the other three treatments after four months phytoremediation.

\subsection{Petroleum hydrocarbon removal}

The AHs and PAHs fractions of the original contaminated soil (before phytoremediation) were reduced after four months of phytoremediation (Fig. 1). The concentration of TPH (sum of AHs and PAHs) was $4407 \mathrm{mg} \mathrm{kg}^{-1}, 3316 \mathrm{mg} \mathrm{kg}^{-1}, 2533 \mathrm{mg} \mathrm{kg}^{-1}$, $2097 \mathrm{mg} \mathrm{kg}^{-1}, 1674 \mathrm{mg} \mathrm{kg}^{-1}, 1443 \mathrm{mg} \mathrm{kg}^{-1}$ in original soil, treatment control, F, FP, FP + D5A, FP + SB respectively. The total AHs decreased by $28.5 \%, 43.1 \%, 52.9 \%, 62.6 \%, 67.9 \%$ and PAHs by $34.7 \%, 38.7 \%, 49.6 \%, 58.1 \%, 62.9 \%$ in control, F, FP, FP + D5A, $\mathrm{FP}+\mathrm{SB}$ respectively. The concentration of $\mathrm{AHs}(\mathrm{C} 8-\mathrm{C} 16)$ was higher in $\mathrm{F}, \mathrm{FP}+\mathrm{D} 5 \mathrm{~A}$ and $\mathrm{FP}+\mathrm{SB}$ compared with original
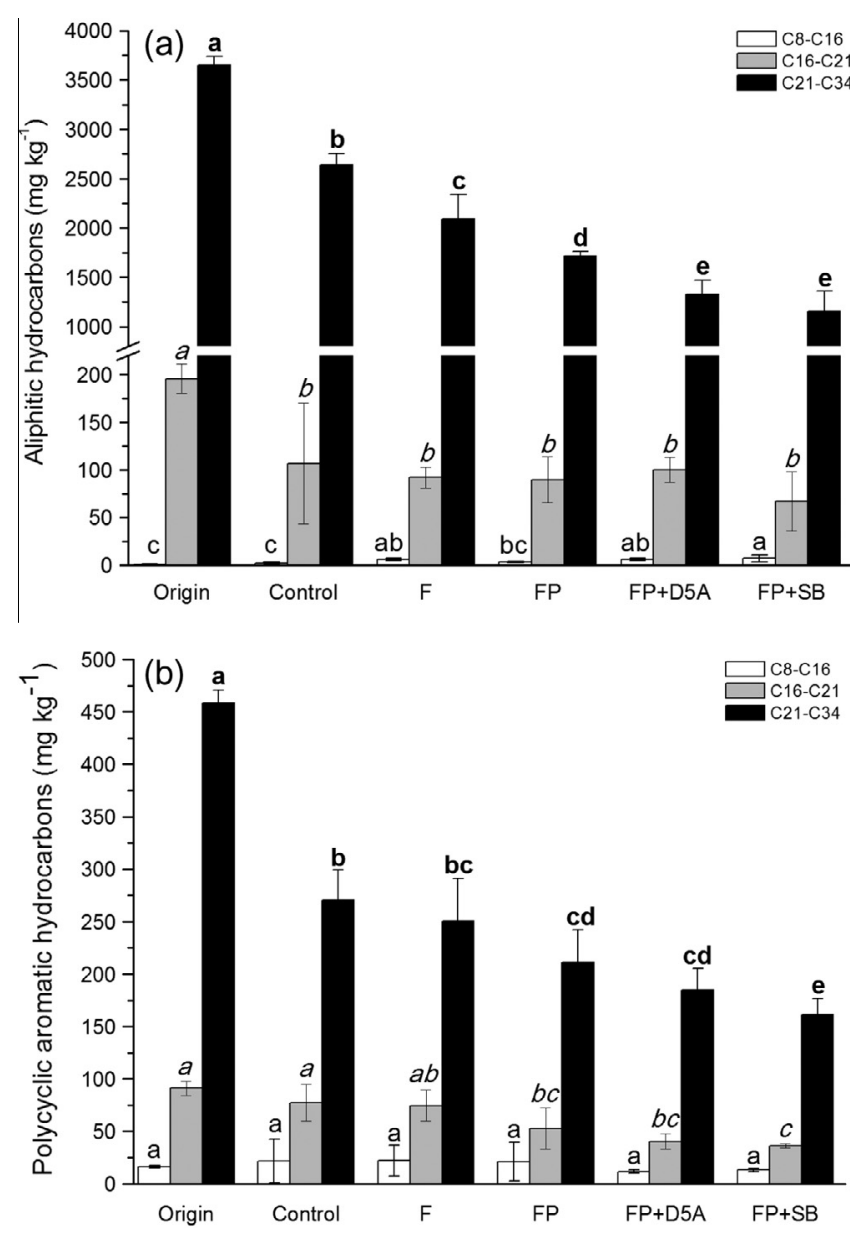

Fig. 1. Aliphatic hydrocarbon (a) and polycyclic aromatic hydrocarbon concentration (b) of different treatments. Vertical bars represent standard deviation $(n=3)$. Letters on columns indicate statistically significant differences for each petroleum fraction among treatments at $p<0.05$ according to Duncan test.

Table 1

Plant biomass and soil properties of different treatments.

\begin{tabular}{|c|c|c|c|c|c|}
\hline & \multicolumn{5}{|l|}{ Treatments } \\
\hline & Control & $\mathrm{F}$ & FP & $\mathrm{FP}+\mathrm{D} 5 \mathrm{~A}$ & $\mathrm{FP}+\mathrm{SB}$ \\
\hline Shoot biomass (dry weight g pot ${ }^{-1}$ ) & - & - & $5.51 \pm 0.13 a$ & $6.09 \pm 0.59 a$ & $6.24 \pm 0.57 a$ \\
\hline Root biomass (dry weight g pot ${ }^{-1}$ ) & - & - & $7.65 \pm 0.94 b$ & $10.0 \pm 1.1 \mathrm{a}$ & $8.39 \pm 1.07 a b$ \\
\hline Total organic matter $\left(\mathrm{g} \mathrm{kg}^{-1}\right.$ soil $)$ & $20.0 \pm 1.3 a$ & $20.0 \pm 0.4 a$ & $19.0 \pm 1.3 a$ & $20.5 \pm 1.8 a$ & $18.4 \pm 1.9 a$ \\
\hline Available phosphorus (mg kg-1 soil) & $4.90 \pm 0.82 \mathrm{c}$ & $21.5 \pm 2.9 \mathrm{a}$ & $13.0 \pm 7.0 b$ & $20.0 \pm 4.2 \mathrm{ab}$ & $19.2 \pm 1.2 \mathrm{ab}$ \\
\hline Available potassium ( $\mathrm{mg} \mathrm{kg}^{-1}$ soil) & $118 \pm 0 a$ & $113 \pm 29 a$ & $108 \pm 9 a$ & $111 \pm 10 a$ & $110 \pm 5 a$ \\
\hline Available nitrogen $\left(\mathrm{mg} \mathrm{kg}^{-1}\right.$ soil) & $30.9 \pm 8.2 b$ & $67.3 \pm 3.7 a$ & $41.9 \pm 10.6 b$ & $37.3 \pm 11.6 b$ & $38.2 \pm 8.0 b$ \\
\hline
\end{tabular}

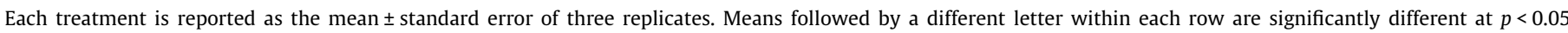
according to the Duncan test. 
contaminated soil and control treatment (Fig. 1a) while there was no significant difference in PAHs (C8-C16) between treatments and original contaminated soil (Fig. 1b). The concentration of AHs (C16-C21) showed no significant difference between different treatments, but was lower than that in original soil (Fig. 1a). For PAHs (C16-C21), concentrations were lower in FP, FP + D5A and $\mathrm{FP}+\mathrm{SB}$ while no significant difference was observed between $\mathrm{F}$, original soil and control (Fig. 1b). The concentration of high molecular weight AHs (C21-C34), which accounted for approximately $81 \%$ of the total petroleum hydrocarbons, was significantly lower $(p<0.05)$ in three treatments with plants compared with that of the control, and the inoculation of SB and D5A further decreased AHs contents. Similar with AHs fraction content, high molecular weight PAHs (C21-C34) decreased more in three planted treatment and the maximum was found in tall fescue + SB.

\subsection{Pyrosequencing and sequence analysis}

A total of 233,924 sequences were obtained after a sequence optimization process, with an average number of 11,615 sequences per sample (ranging from 7639 to 16,358). A total of 7639 reads were subsampled from each replicate for further analysis.

PCoA analysis on Bray-Curtis dissimilarity matrices of OTUs at 97\% cutoff was utilized to further investigate the microbial community differences between the treatments. Analysis showed that samples from the same treatment clustered together and those from different treatments separated (Fig 2). The PCoA plot revealed community level differences between the control, $F$ and plant $(\mathrm{FP}, \mathrm{FP}+\mathrm{D} 5 \mathrm{~A}$ and $\mathrm{FP}+\mathrm{SB})$ microbiota. The first component differentiated treatments based on fertilized and non-fertilized regimes

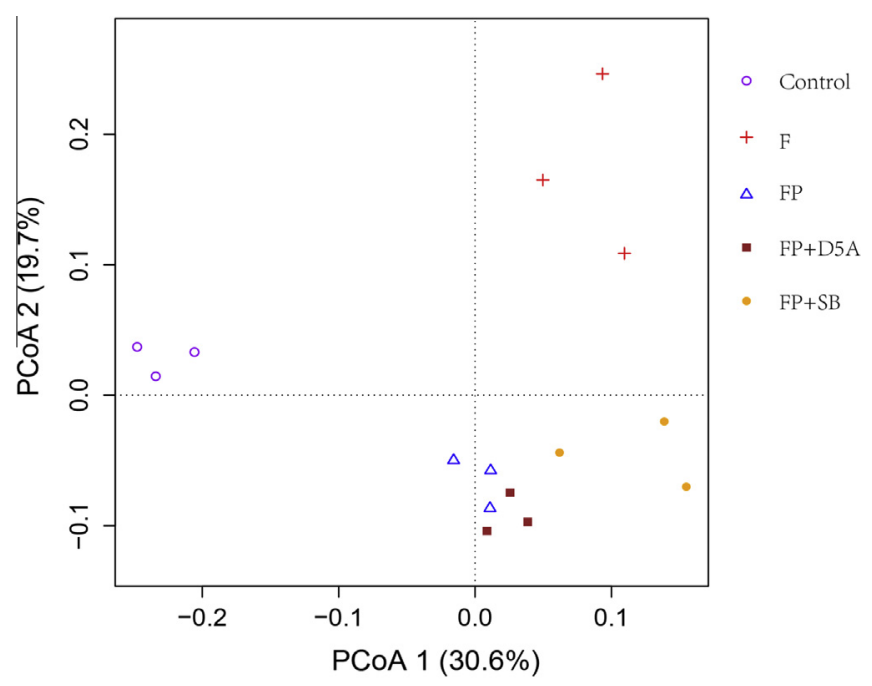

Fig. 2. Comparison of bacterial 16s rRNA communities by different treatments using principle coordination analysis. The percentages in parentheses indicate the proportions of variation by each ordination axis. while the second component differentiated treatments based on the presence or absence of plants.

The calculated bacterial community richness index showed no significant differences in Sobs, Chao and ACE indexes in different treatments Table 2). However, The InvSimpson and Shannon index were significantly lower in the fertilizer treatments than in the control and other treatments with plant (FP, FP + D5A, FP + SB).

\subsection{Taxonomic composition analysis}

Amplified sequences were classified into 23 phyla (Bacteria 21 and Archaea 2). The overall bacterial composition of the different treatments was similar, while the distribution of each phylum or group varied (Fig. 3). In all treatments, Proteobacteria, Actinobacteria, Acidobacteria and Bacteroidetes were the four most dominant phyla, except for the unclassified group, accounting for $>60 \%$ of the sequences in all the treatments. $\gamma$-proteobacteria was the most predominant subclass of Proteobacteria accounting for $46.71-66.99 \%$ of the proteobacterial sequences. In all the detected phyla $\gamma$-proteobacteria and Bacteroidetes increased after fertilization and planting. Inoculation of the Klebsiella sp. strain D5A and Pseudomonas sp. SB, in the rhizosphere soil correlated to an increase in relative abundance at genus level (Fig. 4). Relative abundance of other dominant bacteria, belonging to genus Lysobacter, Pseudoxanthomonas. Perlucidibaca, Ohtaekwangia, Planctomyces, Nocardioides, Hydrogenophaga, increased compared with control and the last five genera also increased compared with F. Redundancy analysis (RDA) indicated these genus positively correlated with high removal efficiency of C8-C16 PAHs, C21-C34 AHs and C21-C34 PAHs in P + PGPR (Fig. 5). C8-C16 AHs, C21-C34 AHs and $\mathrm{C} 21-\mathrm{C} 34 \mathrm{PAHs}$ were three determined factors that contributed significantly $(p<0.05)$ to explaining the variations in community composition in five treatments.

\section{Discussions}

Phytoremediation enhanced by PGPR has been widely implemented to remove organic pollutants such as petroleum hydrocarbons from contaminated soil with great success (Fester et al., 2014). However, the enhancement of the petroleum removal in this process has been frequently shown through measurements of bulk properties like TPH concentration. Such measurements may not be a suitable measure because petroleum is assemblage of complex compounds varying in relative abundance and toxicity, bulk properties analysis cannot provide detailed compositional characteristics of petroleum required to understand its fate (Kim et al., 2013). There are no uniform soil TPH levels in Environmental Quality Standards of many countries range from 1000 to $5000 \mathrm{mg} \mathrm{kg}^{-1}$ (0.1-0.5\%). Therefore, a more appropriate evaluation approach, which combined column chromatography with GC-MS to analyze different petroleum hydrocarbon divisions (AHs and PAHs) and carbon number based fractions (C8-C34), was used in this study.

Table 2

Richness and diversity of 16s rRNA gene sequences from different treatments.

\begin{tabular}{|c|c|c|c|c|c|}
\hline Treatments & Sobs & Chao & Ace & InvSimpson & Shannon \\
\hline Control & $2523 \pm 101 a$ & $8764 \pm 1000 a$ & $15722 \pm 2048 a$ & $295 \pm 30 a$ & $6.80 \pm 0.06 a$ \\
\hline $\mathrm{F}$ & $2279 \pm 238 a$ & $7819 \pm 902 a$ & $15006 \pm 2189 a$ & $64 \pm 36 d$ & $6.16 \pm 0.42 b$ \\
\hline $\mathrm{FP}$ & $2516 \pm 288 a$ & $10122 \pm 3486 a$ & $20522 \pm 8807 a$ & $233 \pm 25 b$ & $6.70 \pm 0.14 a$ \\
\hline $\mathrm{FP}+\mathrm{D} 5 \mathrm{~A}$ & $2416 \pm 137 a$ & $9380 \pm 1619 a$ & $17507 \pm 4126 a$ & $220 \pm 21 b$ & $6.62 \pm 0.02 a$ \\
\hline $\mathrm{FP}+\mathrm{SB}$ & $2325 \pm 94 a$ & $9530 \pm 703 a$ & $18245 \pm 1578 a$ & $136 \pm 31 c$ & $6.42 \pm 0.14 \mathrm{ab}$ \\
\hline
\end{tabular}

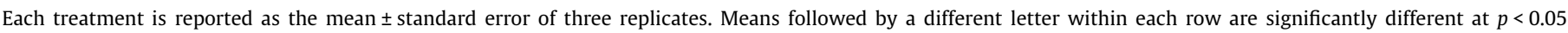
according to the Duncan test. 


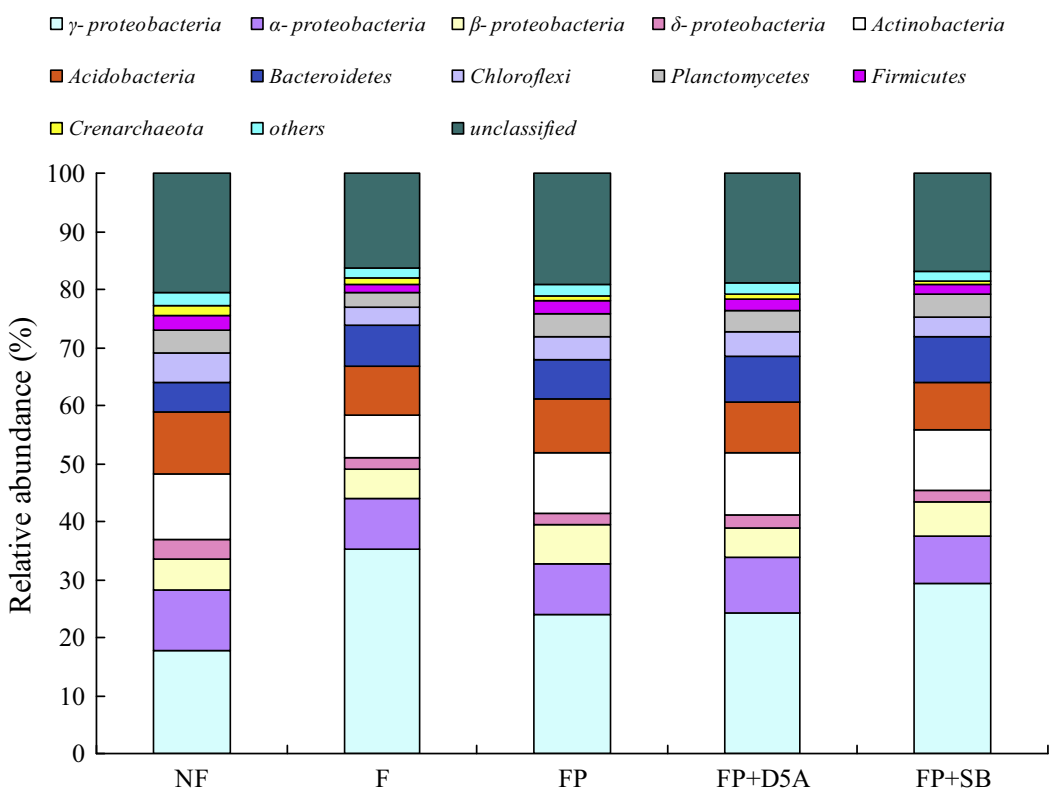

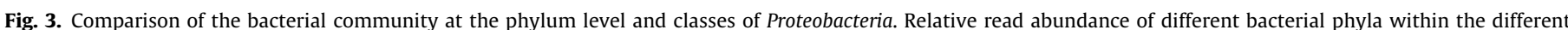

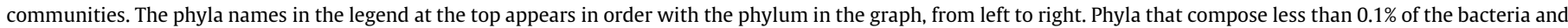
archaea in all treatments are grouped into "Others". Sequences that could not be classified into any known group were assigned as "unclassified".
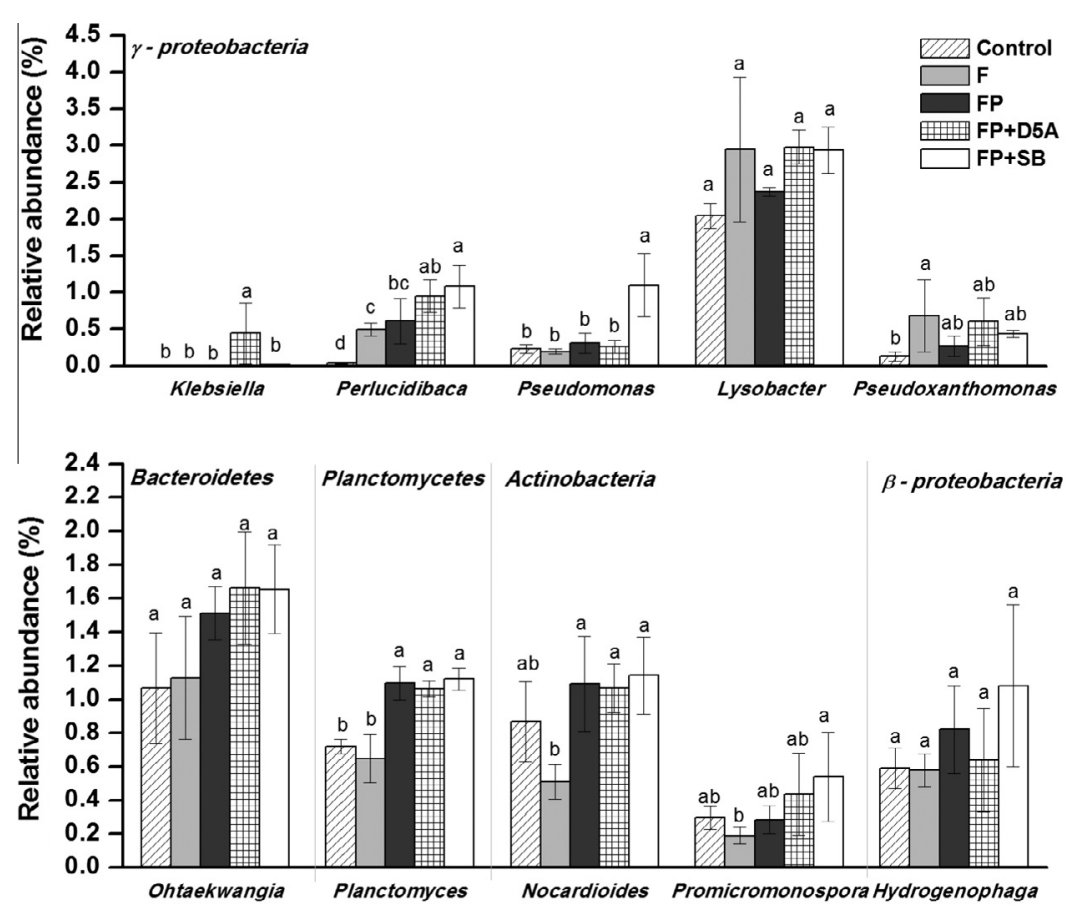

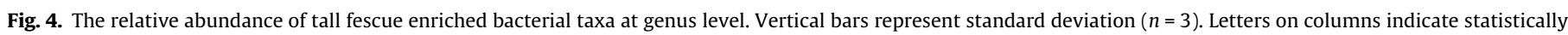
significant differences in relative abundance at $p<0.05$ according to Duncan test.

GC-MS analysis revealed that C21-C34 AHs and C21-C34 PAHs were the dominant components of petroleum in the soil used in this study. This indicates that the soil has been weathered for a long period before sampling for this study due to the relative low molecular weight (C8-C21) petroleum hydrocarbons that had likely been volatilized or been degraded. Significant degradation of AHs and PAHs occurred in all treatments after four months phytoremediation. Interestingly the amount of the most recalcitrant fraction to degradation, $\mathrm{C} 21-\mathrm{C} 34$, was found reduced more in phytoremediation treatments (FP, FP + D5A and FP + SB). C21-C34 AHs significantly reduced in both $\mathrm{FP}+\mathrm{SB}$ and $\mathrm{FP}+\mathrm{D} 5 \mathrm{~A}$ compared with FP while C21-C34 PAHs was removed more from FP + SB than in $\mathrm{FP}+\mathrm{D} 5 \mathrm{~A}$. The C16-C21 AHs fractions showed no obvious change between treatments. In China there is no standard for soil TPH but Control Standards for TPH in Sludges from Agricultural Use (China, GB 4284-84) recommend levels bellow $3000 \mathrm{mg} \mathrm{kg}^{-1}$. 


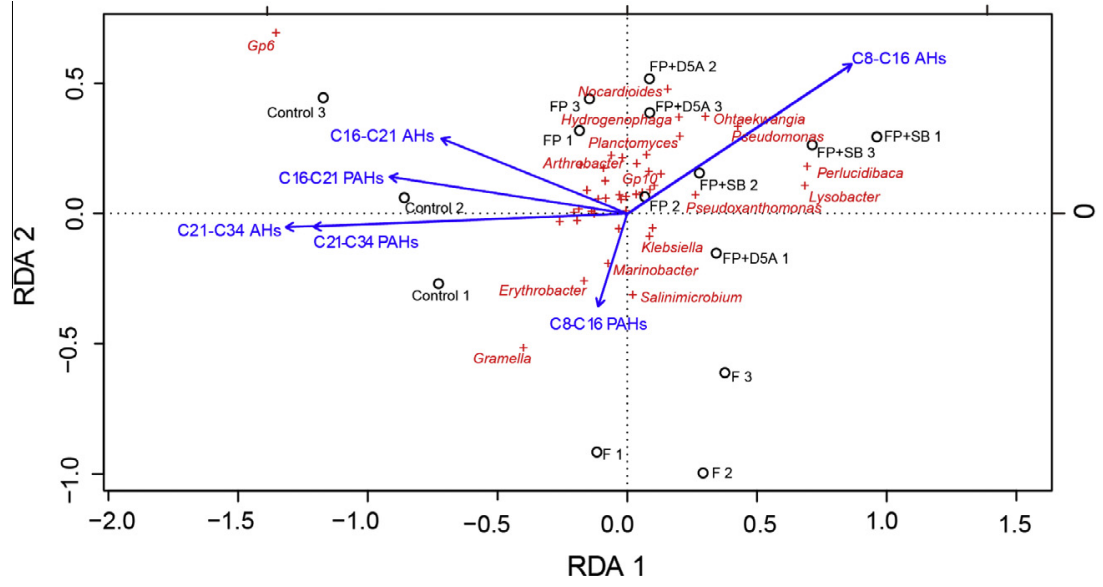

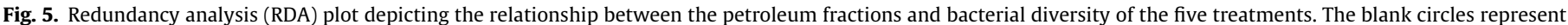

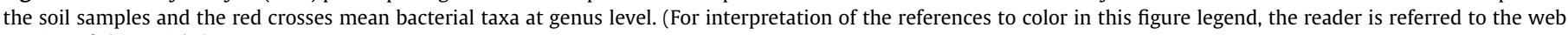
version of this article.)

After bioremediation F, FP, FP + D5A and FP + SB treatments were all below this level. This study elucidated that PGPR inoculation could enhance petroleum removal efficiency during phytoremediation, especially in the recalcitrant fractions. D5A and SB successfully survived in the rhizosphere as assessed by 16s rRNA analysis at genus level. Plant growth, particularly root biomass, (Table 1) was promoted through their beneficial effects of PGPR, which may include production of phytohormones and solubilization of minerals (Liu et al., 2014, 2013). Root biomass may also have other beneficial effects such as increasing pollutant bioavailability, providing habitat for bacterial growth of petroleum degraders as well as co-metabolism process of recalcitrant pollutant, such as PAHs, with the rhizosphere associated microbiota (Martin et al., 2014). Therefore, the biodegradation of the recalcitrant fractions may be enhanced by increasing root biomass and partially responsible for the increased petroleum degradation observed in this study. SB produces biosurfactant (Liu et al., 2013) which may increase solubilization of PAHs, a more hydrophobic compounds than n-alkanes with equivalent carbon numbers, and further enhanced the removal of these recalcitrant hydrocarbons.

The degradation of petroleum hydrocarbons in phytoremediation is general attributed to indigenous microbes, microbial community analysis was preformed by high throughput pyrosequencing to reach a more in-depth understanding of the biological processes of petroleum degradation during rhizoremediation. PCoA analysis (Fig. 2) based on OTU composition showed that bacterial community was observably differentiated between $\mathrm{F}$ and tall fescue planting treatments $(\mathrm{FP}, \mathrm{FP}+\mathrm{D} 5 \mathrm{~A}$ and $\mathrm{FP}+\mathrm{SB})$ whereas the communities of $\mathrm{FP}, \mathrm{FP}+\mathrm{D} 5 \mathrm{~A}$ and $\mathrm{FP}+\mathrm{SB}$ did not diverge significantly. Similarly, the diversity index (Table 2) showed that InvSimpson decreased significantly in $\mathrm{F}, \mathrm{FP}, \mathrm{FP}+\mathrm{D} 5 \mathrm{~A}$ and $\mathrm{FP}+\mathrm{SB}$ compared with control and increased in FP, FP + D5A, FP + SB treatments compared with $\mathrm{F}$ treatment. Both Shannon and InvSimpson index were lowest in treatment $F$, which may be due to the enrichment effect on fast growing bacteria by the nutrient added as $\mathrm{N}$ and $\mathrm{P}$ source. However, the decreased diversity in $\mathrm{F}$ treatment did not slow the removal rate of petroleum hydrocarbon compared with control which is consistent with the study of Bell et al. (2013b). Bell et al. (2013b) suggested that diversity might be important in the initial selection of organisms, but less important for actual hydrocarbon degradation. Not all the microorganisms in soil have the same capacity for nutrient assimilation and subsequent growth. Selective stimulation of fast growing petroleum degraders is more important than general stimulation of the entire community in bioremediation of contaminated soils (Bell et al., 2013a). Therefore, for successful and rapid bioremediation such a dramatic shift in the microbial population was expected and desired.

In this study, a few groups of bacteria appeared to be enriched in planting treatments ( $\mathrm{FP}, \mathrm{FP}+\mathrm{D} 5 \mathrm{~A}$ and $\mathrm{FP}+\mathrm{SB}$ ), especially $\mathrm{FP}+\mathrm{D} 5 \mathrm{~A}$ and $\mathrm{FP}+\mathrm{SB}$. A comparison at the phylum level identified bacteria belonging to the Proteobacteria was the most abundant, and abundance significantly increased after fertilization and planting treatments (Fig. 3). Proteobacteria comprised a group of Gram-negative bacteria that has been extensively reported to degrade petroleum hydrocarbons (Jurelevicius et al., 2013). In the proteobacteial community, $\gamma$ - and $\alpha$-proteobacteia predominated in a manner similar to most studies regarding petroleum contaminated soil. This further highlights their importance during such processes (Matsui et al., 2014). In this study Pseudoxanthomonas, within the $\gamma$-proteobacteria, was enriched in the rhizosphere and showed a relative higher abundance in both PGPR inoculation treatments. Strains of this genus have been previously detected in polluted sites and identified as high molecular weight PAHs degraders (Tejeda-Agredano et al., 2013). The genus Lysobacter dominated $\gamma$-proteobacteria in this study and was favored by fertilizer and planting treatments. It has been reported to produce biosurfactant (Hayward et al., 2010) and reinforce the bioavailability of high lipophilic petroleum hydrocarbons and enhanced their degradation. Some other genera belong to $\beta$-proteobacteria, such as Hydrogenphaga, are also potential petroleum degraders. Hydrogenphaga has been reported could degrade a wide range of contaminants including PAHs (Aburto and Peimbert, 2011).

In addition, the dominated bacterial phyla following proteobacteria were Actinobacteria, Acidobacteria and Bacteroidetes containing hydrocarbon-degrading bacteria (Røberg et al., 2011). Bacteroidetes are Gram-negative heterotrophic bacteria which are common in ecosystems and are known to degrade high-molecular-weight organic compounds, including petroleum hydrocarbons (Drury et al., 2013). Bacteroidetes has been reported to be fast growing and fast acting decomposers of organic matter and increased in abundance after planting. Another dominant phylum, Acidobacteria, has been reported as a slow-acting decomposer tended to decrease in the fertilizer and plant treatments (Tian and Gao, 2014). Other genus enriched in two PGPR inoculation treatments (Fig. 4), such as Ohtaekwangia, Planctomyces, Nocardioides, Hydrogenophaga, have also been researched as potential petroleum hydrocarbon degraders and reported to be involved in PAH degradation (McGenity et al., 2012). A strain of Hydrogenophaga has been 
reported to degrade naphthalene (Song et al., 2006) and Nocardioides can degrade crude oil including PAHs (Schippers et al., 2005). RDA analysis (Fig.5) demonstrated that all aforementioned tall fescue enriched bacteria were positively correlated with the removal of high molecular petroleum hydrocarbons (C21-C34 AHs and PAHs) in this study and confirmed that petroleum degradation was enhanced by a distinct bacterial community.

\section{Conclusion}

In this study, a pot experiment was designed to study the micro-ecological mechanism of PGPR enhanced phytoremediation. Tall fescue biomasses increased by PGPR while petroleum hydrocarbons was removed at the highest level by two PGPR inoculation treatments, particular high molecular weight fractions (C21-C34) of AHs and PAHs. In addition, the removal efficiency was not relative with bacterial diversity but with the selective effect of phytoremediation on specific bacterial communities. Then RDA analysis revealed that Lysobacter, Pseudoxanthomonas, Planctomyces, Nocardioides, Hydrogenophaga, Ohtaekwangia with high relative abundance in FP and FP + PGPR were positively correlated with high molecular weight petroleum hydrocarbons (C21-C34 AHs and C21-C34 PAHs). These results provide us a more in-depth understanding of the biological processes of petroleum degradation during rhizoremediation and indicate that specific bacteria group deserves more attention than bacterial diversity during phytoremediaton of petroleum for better remediation effectiveness.

\section{Acknowledgements}

We thank the National Natural Science Foundation of China (41001182), Jiangsu Provincial Natural Science Foundation of China (BK2012891) and National High Technology Research and Development Program of China (863 Program) (2012AA06A204) for financial support.

\section{References}

Aburto, A., Peimbert, M., 2011. Degradation of a benzene-toluene mixture by hydrocarbon-adapted bacterial communities. Ann. Microbiol. 61, 553-562.

Agarry, S.E., Aremu, M.O., Aworanti, O.A., 2013. Kinetic modelling and half-life study on bioremediation of soil co-contaminated with lubricating motor oil and lead using different bioremediation strategies. Soil Sediment. Contam. 22, 800-816.

Bashan, Y., 1986. Significance of timing and level of inoculation with rhizosphere bacteria on wheat plants. Soil Biol. Biochem. 18, 297-301.

Bell, TH., Yergeau, EF., Juck, DG., Whyte, LW., Greer, C., 2013a. Alteration of microbial community structure affects diesel biodegradation in an Arctic soil. FEMS Microbiol. Ecol. 85, 51-61.

Bell, T.H., Yergeau, E., Maynard, C., Juck, D., Whyte, L.G., Greer, C.W., 2013b. Predictable bacterial composition and hydrocarbon degradation in Arctic soils following diesel and nutrient disturbance. ISME J. 7, 1200-1210.

Bolger, A.M., Lohse, M., Usadel, B., 2014. Trimmomatic: a flexible trimmer for Illumina sequence data. Bioinformatics 30, 2114-2120.

Cook, R.L., Hesterberg, D., 2013. Comparison of trees and grasses for rhizoremediation of petroleum hydrocarbons. Int. J. Phytore. 15, 844-860.

Das, R., Kazy, S.K., 2014. Microbial diversity, community composition and metabolic potential in hydrocarbon contaminated oily sludge: prospects for in situ bioremediation. Environ. Sci. Pollut. Res. 21, 7369-7389.

Drury, B., Rosi-Marshall, E., Kelly, J.J., 2013. Wastewater treatment effluent reduces the abundance and diversity of benthic bacterial communities in urban and suburban rivers. Appl. Environ. Microbiol. 79, 1897-1905.
Fester, T., Giebler, J., Wick, L.Y., Schlosser, D., Kastner, M., 2014. Plant-microbe interactions as drivers of ecosystem functions relevant for the biodegradation of organic contaminants. Curr. Opin. Biotechnol. 27, 168-175.

Hamamura, N., Ward, D.M., Inskeep, W.P., 2013. Effects of petroleum mixture types on soil bacterial population dynamics associated with the biodegradation of hydrocarbons in soil environments. FEMS Microbiol. Ecol. 85, 168-178.

Hayward, A.C., Fegan, N., Fegan, M., Stirling, G.R., 2010. Stenotrophomonas and Lysobacter: ubiquitous plant-associated gamma-proteobacteria of developing significance in applied microbiology. J. Appl. Microbiol. 108, 756-770.

Jurelevicius, D., Alvarez, V.M., Marques, J.M., Lima, L., Dias, F.D., Seldin, L., 2013. Bacterial community response to petroleum hydrocarbon amendments in freshwater, marine, and hypersaline water-containing microcosms. Appl Environ. Microbiol. 79, 5927-5935.

Khan, S., Afzal, M., Iqbal, S., Khan, Q.M., 2013. Plant-bacteria partnerships for the remediation of hydrocarbon contaminated soils. Chemosphere 90 1317-1332.

Kim, M. et al., 2013. Petroleum hydrocarbon contaminations in the intertidal seawater after the Hebei Spirit oil spill-effect of tidal cycle on the TPH concentrations and the chromatographic characterization of seawater extracts. Water Res. 47, 758-768.

Kozich, J.J., Westcott, S.L., Baxter, N.T., Highlander, S.K., Schloss, P.D., 2013 Development of a dual-index sequencing strategy and curation pipeline for analyzing amplicon sequence data on the MiSeq Illumina sequencing platform. Appl. Environ. Microbiol. 79, 5112-5120.

Liu, W., Hou, J., Wang, Q., Ding, L., Luo, Y., 2014. Isolation and characterization of plant growth-promoting rhizobacteria and their effects on phytoremediation of petroleum-contaminated saline-alkali soil. Chemosphere 117, 303-308.

Liu, W.X., Sun, J.Y., Ding, L.L., Luo, Y.M., Chen, M.F., Tang, C.X., 2013. Rhizobacteria (Pseudomonas sp. SB) assist phytoremediation of oily-sludge-contaminated soil by tall fescue (Testuca arundinacea L.). Plant Soil 371, 533-542.

Magoč, T., Salzberg, S.L., 2011. FLASH: fast length adjustment of short reads to improve genome assemblies. Bioinformatics 27, 2957-2963.

Martin, B.C., George, S.J., Price, C.A., Ryan, M.H., Tibbett, M., 2014. The role of root exuded low molecular weight organic anions in facilitating petroleum hydrocarbon degradation: current knowledge and future directions. Sci. Total Environ. 472, 642-653.

Matsui, T., Yamamoto, T., Shinzato, N., Mitsuta, T., Nakano, K., Namihira, T., 2014 Degradation of oil tank sludge using long-chain alkane-degrading bacteria. Ann. Microbiol. 64, 391-395.

McGenity, T.J., Folwell, B.D., McKew, B.A., Sanni, G.O., 2012. Marine crude-oil biodegradation: a central role for interspecies interactions. Aquat. Biosyst. 8, 10 .

Pizarro-Tobías, P. et al., 2015. Field trial on removal of petroleum-hydrocarbon pollutants using a microbial consortium for bioremediation and rhizoremediation. Environ. Microbiol. Rep. 7 (1), 85-94.

Røberg, S., Østerhus, J., Landfald, B., 2011. Dynamics of bacterial community exposed to hydrocarbons and oleophilic fertilizer in high-Arctic intertida beach. Polar Biol. 34, 1455-1465.

Ribeiro, H., Mucha, AP., Marisa, R., Almeida, C., Bordalo, AA., 2013. Bacterial community response to petroleum contamination and nutrient addition in sediments from a temperate salt marsh. Sci. Total Environ. 458, 568-576.

Schippers, A., Schumann, P., Spröer, C., 2005. Nocardioides oleivorans sp. nov. a novel crude-oil-degrading bacterium. Int. J. Syst. Evol. Microbiol. 55, 1501-1504.

Song, H., Oiu, S., Zhang, J., Xia, C.G., 2006. Study on Hydrogenophaga Palleronii LHJ38a naphthalene-degrading strain with high activity. Environ. Protect. Chem. Ind 2, 87-90.

Tejeda-Agredano, M.C., Gallego, S., Vila, J., Grifoll, M., Ortega-Calvo, J.J., Cantos, M., 2013. Influence of the sunflower rhizosphere on the biodegradation of PAHs in soil. Soil Biol. Biochem. 57, 830-840.

Tian, Y., Gao, L., 2014. Bacterial diversity in the rhizosphere of cucumbers grown in soils covering a wide range of cucumber cropping histories and environmental conditions. Microb. Ecol. 68, 794-806.

Wang, Z., Xu, Y., Zhao, J., Li, F., Gao, D., Xing, B., 2011. Remediation of petroleum contaminated soils through composting and rhizosphere degradation. J. Hazard. Mater. 190, 677-685.

Washington State Department of Ecology (WSDE), 1997. Analytical methods for petroleum hydrocarbons. Publication No. ECY 97-602.

Wei, J., Liu, X.Y., Zhang, X.Y., Chen, X.P., Liu, S.S., Chen, L.S., 2014. Rhizosphere effect of Scirpus triqueter on soil microbial structure during phytoremediation of diesel-contaminated wetland. Environ. Technol. 35, 514-520.

Yateem, A., 2013. Rhizoremediation of oil-contaminated sites: a perspective on the Gulf War environmental catastrophe on the State of Kuwait. Environ. Sci. Pollut. Res. 20, 100-107. 